\title{
Understanding, attitudes and dehumanisation towards autistic individuals
}

\author{
Eilidh Cage $^{1}$, Jessica Di Monaco ${ }^{1}$ and Victoria Newell ${ }^{1}$ \\ Department of Psychology, Royal Holloway, University of London, Egham, Surrey, UK, \\ TW20 OEX
}

Manuscript accepted for publication in Autism

$15^{\text {th }}$ October 2018

Author note: Correspondence concerning this article should be addressed to Eilidh Cage, Department of Psychology, Royal Holloway, University of London, Egham Hill, Egham, Surrey, TW20 0EX, Eilidh.cage@ @rhul.ac.uk, telephone: (+44) 1784443707.

The authors declare that there are no potential conflicts of interest with respect to the research, authorship, and/or publication of this article. 


\begin{abstract}
Research suggests that while individuals may self-report positive attitudes towards autism, dehumanising attitudes (seeing another as less than human) may still prevail. The present study investigated knowledge, openness and dehumanising attitudes of non-autistic people towards autistic people. 361 participants completed a survey measuring autism openness, knowledge and experience, along with a measure of dehumanisation. Results showed that knowledge of autism was comparable to past research and females were more open towards autism. Findings also indicated evidence for dehumanisation, with a particular denial of 'human uniqueness' traits. Further, dehumanisation was related to openness towards autism. These findings have implications for targeting attitudes to reduce stigma associated with autism.
\end{abstract}

Keywords: Autism Spectrum Conditions; Autism understanding; attitudes; dehumanisation. 
Autism is a lifelong neurodevelopmental condition, affecting the way individuals process and perceive the world around them. Autism is diagnosed when individuals demonstrate social interaction and social communication difficulties, as well as repetitive behaviours and focused interests (APA, 2013). In the UK, it is estimated that around 1 in every 100 individuals have an autism spectrum condition (Baird et al., 2006). Thus, autism is not rare, and many people will have a connection to autism, either personally - through family or friends - in educational settings or in the workplace. Indeed, surveys of the general public indicate that people are aware of autism and have reasonable knowledge about the condition (Dillenburger, McKerr, Jordan, Devine and Keenan, 2015; Jensen et al., 2016; Tipton and Blacher 2014). However, awareness and understanding does not necessarily equate to acceptance of autism, thus stigmatisation could still occur (Jensen et al., 2016). Stigma can be defined as negative judgements that discredit a person's identity or traits, particularly where that identity or traits deviate from an assumed norm (Goffman, 1990). Goffman (1990) argues that to stigmatise is to see others as less than human. People can engage in explicit stigma (for example, consciously denigrating another group) or implicit stigma (for example, an underlying stigmatising attitude which is not consciously or explicitly reported; Stier and Hinshaw, 2007).

Research looking at stigma towards autism often considers the experiences of parents with an autistic ${ }^{1}$ child. For example, Gray (2002) conducted an interview study with Australian parents of children diagnosed with Asperger's Syndrome, and most parents reported experiencing stigma. Quantitative methods also show that these parents experience and often internalise stigma (Mak and Kwok, 2010). Cross-cultural questionnaire studies with non-autistic people also demonstrate the existence of stigma towards autistic people in

\footnotetext{
${ }^{1}$ In this paper we use identity-first language or 'on the autism spectrum' to respect the preferences of the autism community (Kenny et al., 2016).
} 
countries with few autism services (e.g. Lebanon) and in countries where autism is more visible in the public discourse (e.g. the USA), although there is potentially less explicit stigma in the latter (Obeid et al. 2015). Knowledge of autism and openness towards autistic individuals has also been measured with questionnaire methods, with better understanding and openness found in those with past experience or contact with autistic individuals (Gardiner and Iarocci 2013; Gillespie-Lynch et al. 2015; Nevill and White 2011; White, Hillier, Frye and Makrez, 2016).

Although these surveys indicate an awareness of autism in non-autistic individuals, autistic individuals often report how they feel like services, employers and the general public do not understand autism (Griffith, Totsika, Nash and Hastings, 2012) and that they often experience stigmatisation (Shtayermman, 2009). Indeed, this lack of understanding could be seen as part of the 'double empathy' problem described by Milton (2012). Milton (2012) argues that while autistic people may struggle with social insight into the lives of non-autistic people, the reverse is also true in that non-autistic people also lack social insight into the lives of autistic people. Experimental evidence has supported this view, with non-autistic individuals struggling to identify autistic individuals' emotional expressions (Brewer et al., 2016) and family members underestimating autistic individuals' perspective-taking abilities (Heasman and Gillespie 2017).

Further, some autistic adults discuss how they frequently hide or camouflage their autism diagnosis from others, whereby 'coming out' as an autistic person is viewed as a difficult process (Davidson and Henderson 2010). This camouflaging is also reported elsewhere in the literature (Bargiela, Steward and Mandy, 2016; Dean, Harwood and Kasari, 2016; Hull et al., 2017; Lai et al., 2016; Tierney, Burns and Kilbey, 2017); the necessity to camouflage an autism diagnosis might imply that some autistic individuals feel they would not be accepted or that society would not be supportive of their needs if they 'came out' 
(Davidson and Henderson 2010). Further, striving towards autism acceptance is an important endeavour, since autistic adults who feel less accepted by others also experience more depressive and stress symptoms (Cage, Di Monaco and Newell, 2017). Given the high prevalence of mental health difficulties in autism (Eaves and Ho, 2008), it is vital that we understand and tackle factors such as a lack of autism acceptance which may exacerbate these difficulties.

Surveys of the general public are useful in establishing self-reported knowledge and attitudes towards autism. However, in asking people to self-report how understanding or open they are towards autistic people, these surveys are subject to social desirability and may not reflect a person's true thoughts and opinions. Therefore, it is also important to measure nonautistic individuals' attitudes using a range of different tasks beyond using questionnaires and vignettes. Studies using alternative methodologies imply a lack of autism acceptance. For example, Sasson et al. (2017) found that non-autistic individuals had negative first impressions of autistic people when asked to make judgements about people in ten-second video clips. In their study, participants did not know that half of the people in the videos were autistic, and yet they formed a more negative social evaluation of the autistic people. When participants were informed that the people in the videos were autistic, Sasson and Morrison (2017) found that disclosure of the diagnostic label did serve to improve first impressions. Measures of implicit or automatic attitudes using an Implicit Relational Assessment Procedure (IRAP), where participants' response times to negative and positive words are thought to give insight into their implicit biases, show that even those who work regularly with autistic children still have implicit negative biases against autism (Kelly and BarnesHolmes 2012). Additionally, Kelly and Barnes-Holmes (2012) noted that explicit (conscious, outward) attitudes towards autism were predicted by these implicit negative attitudes. 
Another possible means of examining attitudes is through considering the phenomenon of dehumanisation. In social psychology, dehumanisation is the denial of 'humanness' to others (Haslam, 2006) which could be indicative of stigmatisation and stereotyping (Haslam, Loughnan, Kashima and Bain, 2009). The principles of stigma itself outlined by Goffman (1990) claim that stigmatised groups are seen as 'less human'. One way of testing dehumanisation is by asking participants to rate how much their ingroup and an outgroup show different personality traits. This method is thought to be a subtle means of testing dehumanisation (Kteily, Bruneau, Waytz and Cotterill, 2015). The traits can be divided into two distinct types: uniquely human traits and human nature traits (Haslam, 2006; Haslam et al., 2009). Uniquely human traits are described as unique to humans and not seen in animals, such as broadmindedness and politeness. These traits are thought to delineate humans from other animals, relating to sophisticated cognitive abilities, culture and morality (Haslam, 2006). On the other hand, human nature traits are thought to be innate features typical of all humans, irrespective of culture, such as helpfulness and curiosity, however these traits may not delineate humans from other animals (Haslam, 2006). Importantly these traits are seen as two separate aspects of what makes us human, according to Haslam (2006). Denying someone uniquely human traits suggests that they are seen as more 'child-like' or lacking in self-restraint, and the denial of human nature traits implies that the other is seen as more 'machine-like' or lacking in emotionality or warmth (Bastian and Haslam, 2010; Haslam, 2006).

Haslam (2006) argues that dehumanisation is a naturally occurring socio-cognitive phenomenon, a bias to see one's own group as better than others. Studies tend to show that people assign fewer human traits to an outgroup, therefore perceiving the outgroup as less human (Leyens et al., 2001). For example, this method is used to show that dehumanisation occurs against certain (usually minority) groups of different ethnic, social class and gender 
backgrounds (see Haslam and Loughnan (2014), for a review). Although this method has not been used with autistic people as the outgroup, these methods have shown dehumanisation against physically disabled people (Bodgan and Taylor, 1989) as well as people with intellectual disabilities (Capozza, Di Bernardo, Falvo, Vianello and Calo, 2016). Autistic scholars also argue that autistic people are frequently 'othered' (Milton, 2012) and as a result are arguably seen as an outgroup. We thus predicted that there would be a tendency in nonautistic people to dehumanise autistic people.

The aim of the current study was to establish levels of autism understanding and attitudes in a sample of the non-autistic population, using previously used measures and, for the first time, a dehumanisation measure. It is important that we understand non-autistic individuals' attitudes towards autism so that we can identify ways in which attitudes, and ultimately acceptance, could be improved. We utilised previous measures of autism openness (Nevill and White, 2010) and autism knowledge (Tipton and Blacher, 2014). Considering that participants may explicitly report good understanding and openness towards autism, but still have underlying dehumanising attitudes, dehumanisation methods were also adopted (Bastian and Haslam, 2010). Thus, this study is novel in its use of self-reported attitudes and dehumanising measures to test autism acceptance within the same group of participants. Based on the previous literature described above, we predicted that knowledge and openness towards autism would be good, but participants would also express dehumanising attitudes. We also predicted that previous experience of contact with autistic individuals would have a positive impact on participants' understanding and attitudes towards autism. Finally, we aimed to test the relationships between all of the measures, to test how self-reported knowledge and openness towards autism might relate to dehumanisation. 


\section{Methods}

\section{Participants}

A total of 361 participants were recruited from three main sources: young people (aged 16 to 17; median age 17) recruited through schools in the South East of England and university science days $(n=108)$; first year undergraduate psychology students who completed the survey for course credit ( $n=144$; median age 18); and adults over the age of 18 recruited through word of mouth and social media who completed the survey for entry into a prize draw ( $n=109$; median age 21 ). The 16 to 17 -year-olds were recruited to attempt to increase the diversity in the sample and to also potentially cross-sectionally examine for any age differences in attitudes. Analyses, however, are collapsed across these three groups as preliminary analyses showed that there were no significant differences between groups for any of the reported measures. Demographic information including age, gender, ethnicity and education is presented in Table 1. These demographics show that the sample predominantly consisted of white, heterosexual, female students in their early twenties. All participants gave full informed consent before taking part and ethical approval was obtained through Royal Holloway, University of London. None of the participants had a diagnosis of an autism spectrum condition.

[Insert Table 1 near here]

\section{Materials and Procedure}

Participants completed a number of measures which were presented to them in the order of presentation below. The survey was presented online using the Qualtrics survey platform, except for the participants aged 16 to 17 who completed the survey using pen and paper. At the start, all participants read information regarding the survey before giving informed 
consent. After the measures outlined below, participants completed demographic questions. Data collection took place between April and December 2016 and the survey took around 13 minutes to complete.

\section{Autism openness}

Openness to autism was measured using a vignette adapted by Nevill and White (2011) from Harnum et al. (2007). The vignette describes an adult, 'Jamie', who is autistic, although autism itself is not explicitly mentioned within the vignette. After reading the vignette, participants read seven statements about Jamie which they had to rate on a five-point scale from 'strongly agree' (5) to 'strongly disagree' (1). Example statements include 'this person makes me feel afraid' and 'I would hang out with Jamie in my free time'. A total score is then calculated by summing the responses to the seven statements. Higher scores indicate more openness to autism, with a possible range from 5 to 35 . In the current study, omega values were calculated for all scales (Peters, 2014), and internal consistency for the openness scale was acceptable $(\omega=.77)$. This is comparable with the internal consistency reported by Nevill and White (2011).

\section{Dehumanisation}

Dehumanisation was measured by utilising the methods described by Bastian and Haslam (2010) using traits which have been validated as either 'human nature' or 'human uniqueness' traits by Haslam et al. (2005). Here, participants were asked to rate on a scale from one ('not at all') to seven ('very much') the degree to which different personality traits described autistic and non-autistic people. Specifically, participants were asked "to what degree do the following traits describe people with autism/people who do not have autism". Twenty traits were rated for each group, including ten human nature traits (active, curious, friendly, helpful, fun-loving, impatient, impulsive, jealous, nervous, shy), and ten human 
uniqueness traits (broadminded, conscientious, humble, polite, thorough, disorganised, hardhearted, ignorant, rude, stingy). For each trait grouping (i.e. uniqueness or nature traits) the item scores are averaged, giving each trait group a maximum possible score of seven, with higher scores indicating the traits are very much descriptive of the group in question. For human nature traits, these had acceptable internal consistency for the ratings of non-autistic people $(\omega=.69)$ but poorer internal consistency for ratings of autistic people $(\omega=.54)$. Likewise, internal consistency was marginally acceptable for human uniqueness traits for ratings of non-autistic people $(\omega=.63)$ and poorer for ratings of autistic people $(\omega=.58)$. Previous studies have reported good internal consistency for human uniqueness (.85) and human nature traits (.74; Fousiani, Michaelides \& Dimitropoulou, 2018) although the measure may have low test-retest reliability (Kteily et al., 2015).

\section{Autism knowledge}

Knowledge of autism was measured by using the Autism Awareness Survey described by Tipton and Blacher (2014). Here, participants read 14 statements about autism, and we asked participants to judge each statement as either true or false. Example statements included 'there is a cure for autism' (false) and 'autism is diagnosed more frequently in males than in females' (true). In the current study, we were particularly interested in the percentage of correct responses overall and for each statement. Internal consistency for this measure was marginally acceptable, $\omega=.60$.

\section{Autism experience}

Participants were also asked to report if they had any experience of autism, by selecting options such as whether they had a child, sibling, other relative, colleague or friend with an autism spectrum condition, or if they were autistic themselves. 


\section{Analytic approach}

Analyses are collapsed across the three different participant groups (young people, first year psychology students, and word-of-mouth sample) due to no significant differences between these groups on any of the measures in preliminary analyses. Gender, age and experience of autism were controlled for in all analyses. First, Analysis of Covariance (ANCOVA) was used to see whether participants rated autistic people as having fewer of the traits (nature and uniqueness) than non-autistic people. In this analysis 4 outliers were identified with z-scores greater than 3.29 for any of the trait ratings for autistic or non-autistic people - however, since this comprised less than $5 \%$ of the sample and their inclusion did not change the pattern of results, these outliers were maintained in analyses (Field, 2013). Assumptions for homogeneity were met and sphericity was assumed.

Second, we also examined how dehumanisation related to knowledge and openness. To test these relationships, Multivariate Analysis of Variance (MANOVA) was used to test whether dehumanisation (human nature traits and human uniqueness traits) related to knowledge and openness scores. For this analysis outliers $(n=4)$ with z-scores greater than 3.29 were identified but kept within the analysis as discussed above (Field, 2013). All other assumptions were met (Levene's and Box's Tests $p>.10$ ). 


\section{Results}

\section{Autism experience}

Since we predicted that experience would have an impact on participants' answers, we coded participants into either having experience ( $61.7 \%$ of the sample who reported at least one connection to autism) or no experience of autism (38.3\%, constructed of people who said that they 'do not personally know anyone with autism' or 'I have no experience of autism').

\section{Autism openness}

The mean total openness score across all participants was $25.61(\mathrm{SD}=3.40)$. Percentage agreement and means for each item of the openness measure are shown in Table 2. There was an overall gender difference, with female participants $(\mathrm{M}=25.88, S D=3.40)$ reporting significantly higher openness than male participants $(\mathrm{M}=24.17, S D=2.95), t(353)=-3.64$, $p<.001, d=.54$.

\section{[Insert Table 2 near here]}

\section{Autism knowledge}

On average, participants answered $78.6 \%$ of all the statements correctly. Table 3 shows the percentage correct for each statement, comparing those with and without experience using Chi square. Those with experience were significantly more likely to answer the following statements correctly: 'there is a cure for autism', 'autistic individuals can live independently' and 'autism is diagnosed more frequently in males than females'.

[Insert Table 3 near here]

\section{Dehumanisation}


Figure 1 shows the mean trait ratings for each group. A two (group: autistic or non-autistic) by two (trait type: nature or uniqueness) by two (experience: has experience or none) mixed ANCOVA controlling for gender and age was conducted on the trait ratings. There was a significant main effect of trait type $\left(\mathrm{F}(1,342)=39.09, p^{<.001,} \eta_{\mathrm{p}}{ }^{2}=.10\right)$, with human nature traits rated more highly $(M=4.39)$ than human uniqueness traits $(M=3.79)$. No other main effects were significant, including the covariates (all $p \mathrm{~s}>.19$ ). There was a significant interaction between group and trait $\left(\mathrm{F}(1,342)=10.42, p=.001, \eta_{\mathrm{p}}{ }^{2}=.030\right)$. Post hoc simple effects analyses, using Bonferroni to adjust for multiple comparisons, showed a significant difference between trait ratings for the human uniqueness traits, with non-autistic people being rated more highly on these $(p<.001)$ but there was no difference between ratings of autistic people and non-autistic people for nature traits $(p=.10$; see Figure 1$)$.

\section{[Insert Figure 1 near here]}

There was also a significant interaction between group and experience $(\mathrm{F}(1,342)=4.09, p$ $\left.=.044, \eta_{\mathrm{p}}{ }^{2}=.012\right)$. However, follow-up analyses were inconclusive: simple effects analyses showed that those with experience rated non-autistic people as higher than autistic people on the traits overall (regardless of human nature or uniqueness; $p<.001$ ) and those without experience also rated non-autistic people higher than autistic people $(p<.001)$. There were no significant differences when comparing those with and without experience within each group ( $p \mathrm{~s}>.10$; see Figure 2) An interaction between trait, group and experience was approaching significance $\left(\mathrm{F}(1,338)=3.75, p=.058, \eta_{\mathrm{p}}^{2}=.01\right)$. All other interactions were not significant (ps>.11).

\section{[Insert Figure 2 near here]}

\section{Relationships between measures}


We tested whether openness to autism or knowledge of autism related to dehumanisation of human nature traits and human uniqueness traits. Denial of human nature traits suggests that autistic people are seen as 'child-like' and denial of human uniqueness relates to being seen as 'machine-like'. For this analysis, we first calculated dehumanisation as a difference score between ratings for the in-group (non-autistic people) minus the outgroup (autistic people) for human nature and uniqueness traits. Thus, a positive score would indicate that the individual rated non-autistic people as having more of the traits (and were dehumanising autistic people), and a negative score would indicate they rated autistic people as having more of the traits.

MANOVA was used to test the relationships between variables, with the two dehumanisation scores (human nature and human uniqueness) entered as dependent variables and openness, knowledge, gender, age and experience as independent variables. Using Pillai's Trace, there was a significant effect of openness on dehumanisation $(V=.047, \mathrm{~F}(2$, $\left.335)=8.29, p<.001, \eta_{\mathrm{p}}{ }^{2}=.047\right)$. All other effects were not significant (all $p \mathrm{~s}>.063$ ).

To examine the effect of openness on dehumanisation, follow-up univariate ANOVAs showed that there was only a significant effect of openness on human nature traits $(\mathrm{F}(1,342)$ $\left.=11.65, p<.001, \eta_{\mathrm{p}}^{2}=.034\right)$ but not human uniqueness traits $(p=.32)$. This relationship can be noted in Figure 3, such that those who were more open dehumanised less on human nature traits. 


\section{Discussion}

The current study examined understanding and attitudes towards autistic individuals by utilising a range of measures, including dehumanisation methodology for the first time. We found that knowledge of autism was good in our sample, in line with past research (for example, our sample answered 79\% correctly and Tipton and Blacher's (2014) participants answered $76 \%$ correctly). Those with experience tended to have better knowledge in understanding certain aspects of autism, such as correctly acknowledging that autistic individuals can live independent lives and that there is no cure for autism. Those with more experience likely accumulate better knowledge that counters stereotypical misconceptions about autism. We also found that participants reported good openness overall, with females showing higher openness, supporting previous research (Nevill and White, 2011). In fact, within the broader disability literature, being female is argued to be the most important factor in determining positive attitudes towards disability (Rosenbaum, Armstrong and King, 1988). However, we also found evidence of dehumanisation, with autistic people rated as lower specifically with regards to the human uniqueness traits. Finally, regression analyses showed that openness towards autism related to the dehumanisation difference score for human nature traits.

We utilised Haslam's (2005; Bastian and Haslam, 2010) dehumanisation methods as a means of establishing stigma against autistic people. Here, we found dehumanisation specifically for the human uniqueness traits, suggesting a denial of the aspects of humanness that make us unique as a species (Haslam, 2006). Denial of human uniqueness suggests that autistic people are seen as more 'child-like' or lacking in self-restraint, much in the way that research has also shown that Black people are also dehumanised in this way (Goff, Eberhardt, Williams and Jackson, 2008). It is important to note that groups can be denied either human uniqueness or human nature traits, and not necessarily both (Kteily et al., 2015). In the 
current study, the dehumanisation for human uniqueness may reflect stereotypic views such as seeing autism as a condition found in children. Capozza et al. (2016) also found the denial of human uniqueness for individuals with intellectual disabilities, which they argue fits with common misconceptions and underestimations of the abilities of those with intellectual disabilities. In the current study, dehumanisation of autistic people may also relate to such underestimation of abilities and skills, and the medical model discourse often centred around autism.

An alternative explanation to these findings is that the participants rated some of the traits more highly in non-autistic people because they do have more of these traits (e.g. rude). Autistic people tend to be more rational (Farmer, Baron-Cohen and Skylark, 2017) and are thought to be more honest, for example they are less likely to lie (Sodian and Frith, 1992) and are less likely to be strategic in their self-presentations (Scheeren, Begeer, Banerjee, Meerum Terwogt and Koot, 2010). Therefore, our participants may have been aware of these aspects of autism and rated non-autistic people as being, for example, ruder. Nonetheless, our results still suggest a denial overall of these characteristics to autistic people, which is a key aspect of dehumanisation (Haslam, 2006).

We also found that both those with and without experience dehumanised autistic people. We would argue that experience remains to be an important variable to investigate the contact hypothesis (Allport, 1954) suggests contact with an outgroup can decrease prejudice against that group (Pettigrew and Tropp, 2006). Indeed, research with neurotypical children has suggested that contact can improve knowledge and attitudes towards autistic peers in the classroom (Marvopoulou and Sideridis, 2014). Research also suggests that it is not just the existence of contact but the context of contact that matters: Bottema-Beutel, Kim and Miele (in press) found that undergraduate students were more likely to endorse exclusion of an autistic student in a classroom context, especially if a good grade was at stake. Future 
research could examine in more detail how different types of experience (e.g. as a family member or a teacher) and context could impact on attitudes.

If experience is important in breaking stereotypes, we support the view that autistic adults themselves must be a key source of information for improving non-autistic individuals' attitudes (Gillespie-Lynch et al., 2017). In particular, more research is needed from a neurodiversity perspective, whereby autism is celebrated as an integral part of identity, with unique characteristics being perceived as differences rather than deficits in comparison to non-autistic individuals (Kapp, Gillespie-Lynch, Sherman and Hutman, 2012). Indeed, research has found that online training about autism for university students, which included a discussion of neurodiversity, did decrease stigma and enhance knowledge of autism (Gillespie-Lynch et al., 2015). Studies which take a more medical model perspective - which views autism as a deficit - however, have found more negative attitudes in non-autistic children following their participation in an educational intervention for typical children which described an autistic peer's brain as 'wrong' (Swaim and Morgan, 2001). Further research is needed to fully elucidate the effectiveness of educational interventions for neurotypicals which take a social model or neurodiversity approach.

In regression analyses, dehumanisation scores were first computed as the difference between ratings of non-autistic and autistic people, such that if dehumanising, a positive score would indicate that non-autistic people were rated consistently more positively than autistic people on the traits. We found that these dehumanisation scores for human nature traits were related to openness, such that those who were less open dehumanised more in terms of nature traits. It is interesting that openness related to dehumanisation of nature traits but not uniqueness, given that we noted specific dehumanisation overall on human uniqueness. As discussed above, it may be the case that the denial of human uniqueness is a response to general stereotyped views around 'child-like' perceptions of autism. The denial 
of human nature traits may relate more to individual differences in openness towards autism. Being less open could contribute to these participants' dehumanising attitudes specifically around their perceptions of autistic people having fewer of the human nature traits, such as being less warm or emotional. Those who are less open may be more likely to endorse stereotypes that autistic people lack empathy, even if this is a myth: research shows that difficulties in emotion processing is better explained by alexithymia than autism (e.g., Bird and Cook, 2013; Bird \& Viding, 2014, Cook, Brewer, Shah and Bird, 2013).

It is important that future research examines other variables that might contribute to the dehumanisation of autistic people. For example, a wide range of moderators of dehumanisation have been identified in the social psychology literature, such as right-wing authoritarianism and social dominance orientation, with those higher in these traits tending to show more dehumanisation (Vaes, Leyens, Paladine and Miranda, 2012). Future research should take into account participants' wider world views, empathy and values.

\section{Limitations}

This study has a number of limitations. It relies on self-report within a questionnaire and our sample were predominantly white female students, thus there was a lack of diversity in our sample impacting on the generalisability of our findings. We also found only small effect sizes within our results. Some of our participants may have taken the survey because they had pre-existing interest in autism, or females may be more likely to complete surveys (Sax, Gilmartin and Bryant 2013). However, we did have some diversity in our sample by also recruiting young people aged 16 to 17 who were partaking in university Open or Science Days without prior knowledge that they would be partaking in this survey. Overall, the mean age of our sample was also young, with most participants in the age range of 18 to 21 . Interestingly, age did not impact on our results, which suggests that by the age of 16 we may 
have acquired knowledge and attitudes towards autism that may not change over time. However, our study can only offer a 'snapshot' of attitudes in one point in time and results may be different with more males included or older people. Longitudinal studies would be beneficial in tracing attitudes in childhood through to adolescence and adulthood, so that we can target negative attitude formation with educational interventions if necessary.

Another limitation is that the openness measure used a vignette in which the protagonist was not labelled as autistic, whereas in the dehumanisation measure autism was explicitly mentioned. Interestingly, the labelling of autism has been found to result in more positive first impressions (Sasson and Morrison, 2017). Research with typical children also shows that including the label of autism alongside descriptive and explanatory information can improve attitudes (Campbell, Ferguson, Herzinger, Jackson and Marino, 2004). In the current study, with the dehumanisation measure no explanatory information was provided, although participants may have been primed by the vignette in the openness measure. Despite this limitation, our findings still indicate the existence of dehumanisation towards autistic people. These findings fit with other research looking at dehumanisation towards a wide range of minority groups such as Black Americans and refugees (Haslam and Stratemeyer, 2016) which suggests that when labelled according to minority group status, dehumanisation can occur.

To the best of our knowledge, this is the first study to apply dehumanisation methods to non-autistic people's attitudes towards autism (Haslam, 2005). One may question the validity of using this measure in this context, as we did find that internal consistency was lower for traits ascribed to autistic people, although the internal consistency of the other traits was acceptable. The poor internal consistency of the measure in comparison to past research with other groups as the outgroup (e.g. Fousiani et al., 2018) could relate to participants in the current study showing greater variation across each trait item rating particularly for autistic 
people. Kteily et al. (2015) compared both subtle measures (such as that used in the current study) and blatant measures (e.g. where participants rate their agreement with outwardly dehumanising statements towards an outgroup) of dehumanisation. They found that their blatant measure of dehumanisation tended to be much more reliable and more sensitive than subtle measures. Replication of the current study would therefore be beneficial, as well as testing dehumanisation using a range of different dehumanisation methodologies which are found in the literature, including more blatant measures (see Haslam and Stratemeyer (2016) for a review). Future studies could also use different vignettes to measure openness towards autism, given the heterogeneity within autistic individuals and one vignette being insufficient to capture this heterogeneity. Nonetheless, our study does add to the scant literature on alternative methodologies which have also previously demonstrated negative attitudes are prevalent towards autistic individuals (Kelly and Barnes-Holmes, 2012; Sasson et al., 2017).

\section{Conclusion}

The current study demonstrated that non-autistic individuals can dehumanise those on the autism spectrum. Dehumanisation is an important aspect of stigma (Goffman, 1990), thus we add to the literature on the attitudes of non-autistic people towards autistic people. We also identified variables which are potentially important for tackling dehumanisation - such as openness and experience. Therefore, we are hopeful that attitudes towards autism are not set in stone, but have the potential to be changed for the better. 


\section{Acknowledgements}

Thank you to all of the participants of this research and to the autistic adults who kindly reviewed an early research proposal for this work.

\section{References}

American Psychiatric Association (2013). Diagnostic and Statistical Manual of Mental Disorders (Fifth edition). Arlington, VA: American Psychiatric Publishing.

Allport, GW (1954). The Nature of Prejudice. Reading, MA: Addison-Wesley.

Baird G, Simonoff E, Pickles A, et al. (2006). Prevalence of disorders of the autism spectrum in a population cohort of children in South Thames: The Special Needs and Autism Project (SNAP). The Lancet 368(9531): 210-215.

Bargiela S, Steward R and Mandy W (2016). The Experiences of Late-diagnosed Women with Autism Spectrum Conditions: An Investigation of the Female Autism Phenotype. Journal of Autism and Developmental Disorders 46(10): 3281-3294.

Bastian B and Haslam N (2010). Excluded from humanity: The dehumanizing effects of social ostracism. Journal of Experimental Social Psychology 46(1): 107-113.

Bird, G and Cook, R (2013). Mixed emotions: the contribution of alexithymia to the emotional symptoms of autism. Translational Psychiatry, 3(7): p.e285.

Bird, G and Viding, E (2014). The self to other model of empathy: providing a new framework for understanding empathy impairments in psychopathy, autism, and alexithymia. Neuroscience \& Biobehavioral Reviews, 47: 520-532.

Bogdan R and Taylor SJ (1989). Relationships with Severely Disabled People: The Social Construction of Humanness. Social Problems 36(2): 135-148. 
Brewer R, Biotti F, Catmur C, et al. (2016). Can Neurotypical Individuals Read Autistic Facial Expressions? Atypical Production of Emotional Facial Expressions in Autism Spectrum Disorders. Autism Research 9(2): 262-271.

Cage E, Monaco JD and Newell V (2017). Experiences of Autism Acceptance and Mental Health in Autistic Adults. Journal of Autism and Developmental Disorders: 1-12.

Campbell, JM, Ferguson, JE, Herzinger, CV, Jackson, JN, and Marino, CA (2004). Combined descriptive and explanatory information improves peers' perceptions of autism. Research in Developmental Disabilities, 25(4): 321-339.

Capozza D, Di Bernardo GA, Falvo R, et al. (2016). Individuals with intellectual and developmental disabilities: Do educators assign them a fully human status? Journal of Applied Social Psychology 46(9): 497-509.

Cook, R, Brewer, R, Shah, P and Bird, G (2013). Alexithymia, not autism, predicts poor recognition of emotional facial expressions. Psychological Science, 24(5): 723-732.

Davidson J and Henderson VL (2010). 'Coming out' on the spectrum: autism, identity and disclosure. Social \& Cultural Geography 11(2): 155-170.

Dean M, Harwood R and Kasari C (2016). The art of camouflage: Gender differences in the social behaviors of girls and boys with autism spectrum disorder. Autism: The International Journal of Research and Practice.

Dillenburger K, McKerr L, Jordan JA, et al. (2015). Creating an Inclusive Society... How Close are We in Relation to Autism Spectrum Disorder? A General Population Survey. Journal of Applied Research in Intellectual Disabilities 28(4): 330-340.

Eaves LC and Ho HH (2008). Young adult outcome of autism spectrum disorders. Journal of Autism and Developmental Disorders 38(4): 739-747. 
Farmer GD, Baron-Cohen S and Skylark WJ (2017). People With Autism Spectrum Conditions Make More Consistent Decisions. Psychological Science: 0956797617694867.

Field, A (2013). Discovering statistics using IBM SPSS statistics ( $3^{\text {rd }}$ edn). London: Sage.

Fousiani, K., Michaelides, M., \& Dimitropoulou, P. (2018). The effects of ethnic group membership on bullying at school: when do observers dehumanize bullies? The Journal of Social Psychology, 1-12.

Gardiner E and Iarocci G (2014). Students with Autism Spectrum Disorder in the University Context: Peer Acceptance Predicts Intention to Volunteer. Journal of Autism and Developmental Disorders 44(5): 1008-1017.

Gillespie-Lynch K, Brooks PJ, Someki F, et al. (2015). Changing College Students' Conceptions of Autism: An Online Training to Increase Knowledge and Decrease Stigma. Journal of Autism and Developmental Disorders 45(8): 2553-2566.

Gillespie-Lynch K, Kapp SK, Brooks PJ, et al. (2017). Whose Expertise Is It? Evidence for Autistic Adults as Critical Autism Experts. Frontiers in Psychology 8: 438.

Goffman, E (1990). Stigma: Notes on the management of spoiled identity ( $3^{\text {rd }}$ Edition). London: Penguin Books.

Goff, PA, Eberhardt, JL, Williams, MJ and Jackson, MC (2008). Not yet human: implicit knowledge, historical dehumanization, and contemporary consequences. Journal of Personality and Social Psychology, 94(2): 292-306.

Gray, DE (2002). 'Everybody just freezes. Everybody is just embarrassed': Felt and enacted stigma among parents of children with high functioning autism. Sociology of Health \& Illness, 24(6): 734-749. 
Griffith GM, Totsika V, Nash S, et al. (2012). 'I just don’t fit anywhere': support experiences and future support needs of individuals with Asperger syndrome in middle adulthood. Autism 16(5): 532-546.

Harnum M, Duffy J and Ferguson DA (2007). Adults' Versus Children's Perceptions of a Child with Autism or Attention Deficit Hyperactivity Disorder. Journal of Autism and Developmental Disorders 37(7): 1337-1343.

Haslam N (2006). Dehumanization: An Integrative Review. Personality and Social Psychology Review 10(3): 252-264.

Haslam N and Loughnan S (2014). Dehumanization and Infrahumanization. Annual Review of Psychology 65(1): 399-423.

Haslam N and Stratemeyer M (2016). Recent research on dehumanization. Current Opinion in Psychology, Intergroup relations 11: 25-29.

Haslam N, Bain P, Douge L, et al. (2005). More human than you: attributing humanness to self and others. Journal of Personality and Social Psychology 89(6): 937-950.

Haslam N, Loughnan S, Kashima Y, et al. (2009). Attributing and denying humanness to others. European Review of Social Psychology 19(1): 55-85.

Heasman B and Gillespie A (2017). Perspective-taking is two-sided: Misunderstandings between people with Asperger's syndrome and their family members. Autism: 1362361317708287.

Hull L, Petrides KV, Allison C, et al. (2017). "Putting on My Best Normal”: Social Camouflaging in Adults with Autism Spectrum Conditions. Journal of Autism and Developmental Disorders 47(8): 2519-2534. 
Jensen CM, Martens CS, Nikolajsen ND, et al. (2016). What do the general population know, believe and feel about individuals with autism and schizophrenia: Results from a comparative survey in Denmark. Autism: The International Journal of Research and Practice 20(4): 496-508.

Kapp SK, Gillespie-lynch K, Sherman LE, et al. (2013). Deficit, Difference, or Both? Autism and Neurodiversity. Developmental Psychology 49(1): 59-71.

Kelly A and Barnes-Holmes D (2013). Implicit attitudes towards children with autism versus normally developing children as predictors of professional burnout and psychopathology. Research in Developmental Disabilities 34(1): 17-28.

Kenny L, Hattersley C, Molins B, et al. (2016). Which terms should be used to describe autism? Perspectives from the UK autism community. Autism 20(4): 442-462.

Bottema-Beutel, K., Kim, S.Y. \& Miele, D.B. (in press). College students' evaluations and reasoning about exclusion of students with autism and learning disability: context and goals may matter more than contact. Journal of Autism and Developmental Disorders. https://doi.org/10.1007/s10803-018-3769-5.

Kteily, N, Bruneau, E, Waytz, A and Cotterill, S (2015). The ascent of man: Theoretical and empirical evidence for blatant dehumanization. Journal of Personality and Social Psychology, 109(5): 901.

Lai M-C, Lombardo MV, Ruigrok AN, et al. (2016). Quantifying and exploring camouflaging in men and women with autism. Autism: 1362361316671012.

Leyens J-P, Rodriguez-Perez A, Rodriguez-Torres R, et al. (2001). Psychological essentialism and the differential attribution of uniquely human emotions to ingroups and outgroups. European Journal of Social Psychology 31(4): 395-411. 
Mak, WW, and Kwok, YT (2010). Internalization of stigma for parents of children with autism spectrum disorder in Hong Kong. Social Science \& Medicine, 70(12): 20452051.

Mavropoulou S and Sideridis GD (2014). Knowledge of Autism and Attitudes of Children Towards Their Partially Integrated Peers with Autism Spectrum Disorders. Journal of Autism and Developmental Disorders 44(8): 1867-1885.

Milton DEM (2012). On the ontological status of autism: the 'double empathy problem'. Disability \& Society 27(6): 883-887.

Nevill REA and White SW (2011). College Students' Openness Toward Autism Spectrum Disorders: Improving Peer Acceptance. Journal of Autism and Developmental Disorders 41(12): 1619-1628.

Obeid, R, Daou, N, DeNigris, D, Shane-Simpson, C, Brooks, PJ, \& Gillespie-Lynch, K (2015). A cross-cultural comparison of knowledge and stigma associated with autism spectrum disorder among college students in Lebanon and the United States. Journal of Autism and Developmental Disorders, 45(11): 3520-3536.

Peters G-JY (2014). The alpha and the omega of scale reliability and validity: Why and how to abandon Cronbach's alpha and the route towards more comprehensive assessment of scale quality. European Health Psychologist 16(2): 56-69.

Rosenbaum PL, Armstrong RW and King SM (1988). Determinants of Children's Attitudes Toward Disability: A Review of Evidence. Children's Health Care 17(1): 32-39.

Sasson NJ, Faso DJ, Nugent J, et al. (2017). Neurotypical Peers are Less Willing to Interact with Those with Autism based on Thin Slice Judgments. Scientific Reports 7: srep40700. 
Sasson, NJ and Morrison, KE (2017). First impressions of adults with autism improve with diagnostic disclosure and increased autism knowledge of peers. Autism, p.1362361317729526.

Sax, L. J., Gilmartin, S. K., \& Bryant, A. N. (2003). Assessing response rates and nonresponse bias in web and paper surveys. Research in Higher Education, 44(4), 409432.

Scheeren AM, Begeer S, Banerjee R, et al. (2010). Can you tell me something about yourself?: Self-presentation in children and adolescents with high functioning autism spectrum disorder in hypothetical and real life situations. Autism 14(5): 457-473.

Shtayermman, O (2009). An exploratory study of the stigma associated with a diagnosis of Asperger's syndrome: The mental health impact on the adolescents and young adults diagnosed with a disability with a social nature. Journal of Human Behavior in the Social Environment, 19(3): 298-313.

Sodian B and Frith U (1992). Deception and Sabotage in Autistic, Retarded and Normal Children. Journal of Child Psychology and Psychiatry 33(3): 591-605.

Stier, A and Hinshaw, SP (2007). Explicit and implicit stigma against individuals with mental illness. Australian Psychologist, 42(2): 106-117.

Swaim KF and Morgan SB (2001). Children's Attitudes and Behavioral Intentions Toward a Peer with Autistic Behaviors: Does a Brief Educational Intervention Have an Effect? Journal of Autism and Developmental Disorders 31(2): 195-205.

Tierney S, Burns J and Kilbey E (2016). Looking behind the mask: Social coping strategies of girls on the autistic spectrum. Research in Autism Spectrum Disorders 23: 73-83. 
Tipton LA and Blacher J (2014). Brief Report: Autism Awareness: Views from a Campus Community. Journal of Autism and Developmental Disorders 44(2): 477-483.

Vaes, J., Leyens, J.P., Paladino, MP and Miranda, MP (2012). We are human, they are not: Driving forces behind outgroup dehumanisation and the humanisation of the ingroup. European Review of Social Psychology, 23(1): 64-106.

White D, Hillier A, Frye A, et al. (2016). College Students' Knowledge and Attitudes Towards Students on the Autism Spectrum. Journal of Autism and Developmental Disorders: $1-7$. 
Table 1. Demographic information for participants on gender, age, sexual identity, employment and education.

Variable

Gender (M:F)

$60: 297 *$

Age

$21.44(\mathrm{SD}=9.99)$

Sexual identity

$\begin{array}{ll}\text { \% Heterosexual } & 87.1 \\ \text { \% Gay/Lesbian } & 2.5 \\ \% \text { Bisexual } & 6.4 \\ \text { \% Don't know } & 1.7 \\ \text { \% Other } & 1.1 \\ \text { \% Prefer not to say } & 1.1\end{array}$

Employment

$\begin{array}{ll}\text { \% Full-time employment } & 6.7 \\ \text { \% Part-time employment } & 6.7 \\ \text { \% Self-employed } & 1.4 \\ \text { \% Unemployed } & 3.1 \\ \text { \% Retired } & 1.1 \\ \text { \% Student } & 79.6 \\ \text { \% Carer } & .8 \\ \text { \% Prefer not to say } & .6\end{array}$

Ethnicity

$\begin{array}{ll}\text { \% White British } & 55.5 \\ \text { \% Other White background } & 14.46 \\ \text { \% Mixed ethnicity } & 4.8 \\ \text { \% Asian } & 19 \\ \text { \% Black/African/Caribbean } & 3.4 \\ \text { \% Other } & 2.5 \\ \text { \% Prefer not to say } & .3\end{array}$


Highest level of education

$\% 1$ to 4 GCSEs or equivalent 1.4

$\%$ 5+ GCSEs or equivalent $\quad 2.0$

$\% 2+$ A-levels or equivalent $\quad 79.6$

$\%$ Undergraduate degree $\quad 10.4$

$\%$ Masters degree $\quad 4.2$

$\%$ Other qualifications $\quad 1.4$

$\%$ Prefer not to say $\quad 1.1$

*One participant identified as Transgender and 3 participants did not provide this information. 
Table 2. Mean (SD) scores for each item of Nevill and White's (2011) autism openness measure, with agreement percentages for each item.

\begin{tabular}{|c|c|c|c|c|c|c|}
\hline Item & Mean $(S D)$ & $\begin{array}{l}\text { Strongly } \\
\text { agree }\end{array}$ & Agree & $\begin{array}{l}\text { Don't } \\
\text { know }\end{array}$ & Disagree & $\begin{array}{l}\text { Disagree } \\
\text { strongly }\end{array}$ \\
\hline $\begin{array}{l}\text { This person makes me feel } \\
\text { afraid* }\end{array}$ & $4.31(.74)$ & $0 \%$ & $4.4 \%$ & $3.6 \%$ & $48.9 \%$ & $43.1 \%$ \\
\hline $\begin{array}{l}\text { This person is probably as } \\
\text { smart as I am }\end{array}$ & $2.23(.84)$ & $18.9 \%$ & $46.7 \%$ & $27.8 \%$ & & $.6 \%$ \\
\hline $\begin{array}{l}\text { I would not mind Jamie } \\
\text { living in my street or } \\
\text { apartment building }\end{array}$ & $1.66(.69)$ & $43.3 \%$ & $50.0 \%$ & $4.2 \%$ & $2.2 \%$ & $.3 \%$ \\
\hline $\begin{array}{l}\text { I would hang out with } \\
\text { Jamie in my free time }\end{array}$ & $2.67(.84)$ & $6.9 \%$ & $5.3 \%$ & $43.1 \%$ & $13.6 \%$ & $1.1 \%$ \\
\hline $\begin{array}{l}\text { I would feel comfortable } \\
\text { around this person }\end{array}$ & $2.40(.85)$ & $11.7 \%$ & $48.9 \%$ & $28.1 \%$ & $10.8 \%$ & $.6 \%$ \\
\hline $\begin{array}{l}\text { This person is different } \\
\text { from me* }\end{array}$ & $2.33(.91)$ & $10.9 \%$ & $62.1 \%$ & $12.5 \%$ & $12.0 \%$ & $2.5 \%$ \\
\hline $\begin{array}{l}\text { Overall, I would like Jamie } \\
\text { as a person }\end{array}$ & $2.05(.64)$ & $16.7 \%$ & $62.7 \%$ & $19.5 \%$ & $1.1 \%$ & $0 \%$ \\
\hline
\end{tabular}

*Items 1 and 6 are reverse scored in the calculation of total openness. 
Table 3. Percentage correct for autism knowledge statements, in descending order from the most to least correct statement, and differences between those with and without experience.

Total correct Experience No experience $p$

\begin{tabular}{|c|c|c|c|c|}
\hline $\begin{array}{l}\text { There is one intervention that works } \\
\text { for all autistic individuals }(\mathrm{F})\end{array}$ & $95.80 \%$ & $96.40 \%$ & $94.90 \%$ & 0.5 \\
\hline There is a cure for autism $(\mathrm{F})$ & $92.20 \%$ & $95 \%$ & $87.70 \%$ & 0.01 \\
\hline $\begin{array}{l}\text { Vaccines are causing an increase in } \\
\text { autism }(F)\end{array}$ & $88.10 \%$ & $88.20 \%$ & & 0.88 \\
\hline $\begin{array}{l}\text { Autistic individuals can live } \\
\text { independently }(\mathrm{T})\end{array}$ & $88.00 \%$ & & $79.60 \%$ & $<.001$ \\
\hline $\begin{array}{l}\text { Autistic individuals are smarter than } \\
\text { standardised tests demonstrate }(\mathrm{T})\end{array}$ & $86.40 \%$ & $87.30 \%$ & $84.80 \%$ & 0.49 \\
\hline $\begin{array}{l}\text { Autism can be diagnosed as early as } \\
18 \text { months }(\mathrm{T})\end{array}$ & $83.30 \%$ & $82.80 \%$ & $84.10 \%$ & 0.76 \\
\hline $\begin{array}{l}\text { With the proper treatment, most } \\
\text { autistic individuals will eventually } \\
\text { outgrow it }(\mathrm{F})\end{array}$ & $81.60 \%$ & $84.60 \%$ & $76.80 \%$ & 0.06 \\
\hline $\begin{array}{l}\text { Autism is diagnosed more frequently } \\
\text { in males than females }(\mathrm{T})\end{array}$ & $80.50 \%$ & $83.70 \%$ & $75.40 \%$ & 0.05 \\
\hline $\begin{array}{l}\text { Changing an autistic individual's } \\
\text { diet will lessen the severity of autism } \\
\text { symptoms (F) }\end{array}$ & $79.10 \%$ & $77.80 \%$ & $81.20 \%$ & 0.45 \\
\hline $\begin{array}{l}\text { It is important that all autistic } \\
\text { individuals receive special education } \\
\text { services }(T)\end{array}$ & $79.10 \%$ & $76.80 \%$ & $82.60 \%$ & 0.20 \\
\hline
\end{tabular}


Autism is a developmental disorder

(T)

Autism runs in families (T)

Autism is an emotional disorder (F) $56.30 \%$

Autistic individuals display poor eye $55.20 \%$ contact $(\mathrm{F})$
$71 \%$

$75 \%$

0.42

$62 \%$

$62.40 \% \quad 61.30 \%$

0.83

$56.10 \%$

$56.50 \%$

0.94

$56.10 \% \quad 53.60 \%$

0.65 


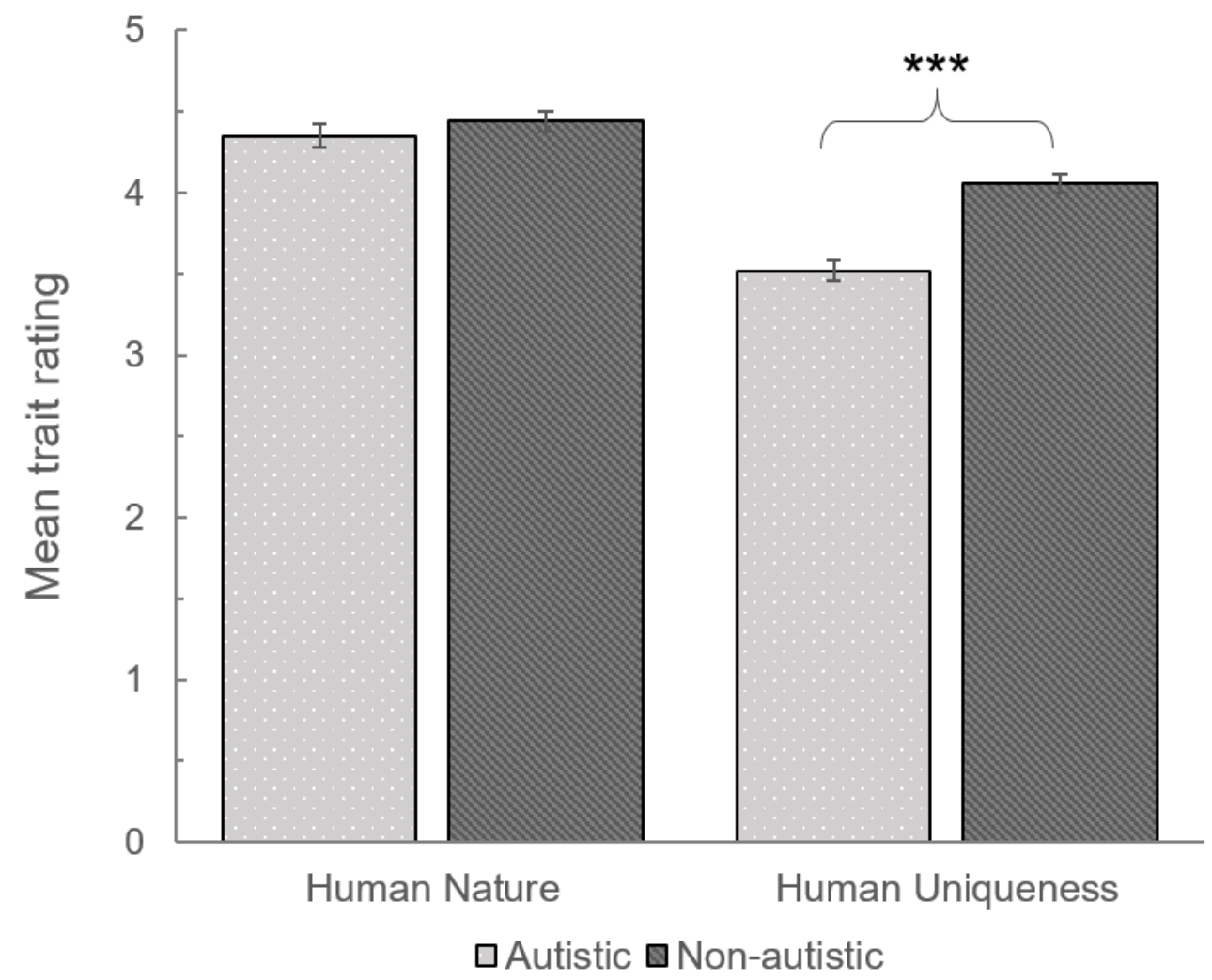

Figure 1. Mean ratings for the human nature and human uniqueness traits of autistic and nonautistic people. Note $* * * \mathrm{p}<.001$. Error bars indicate $+/-2$ SE. 


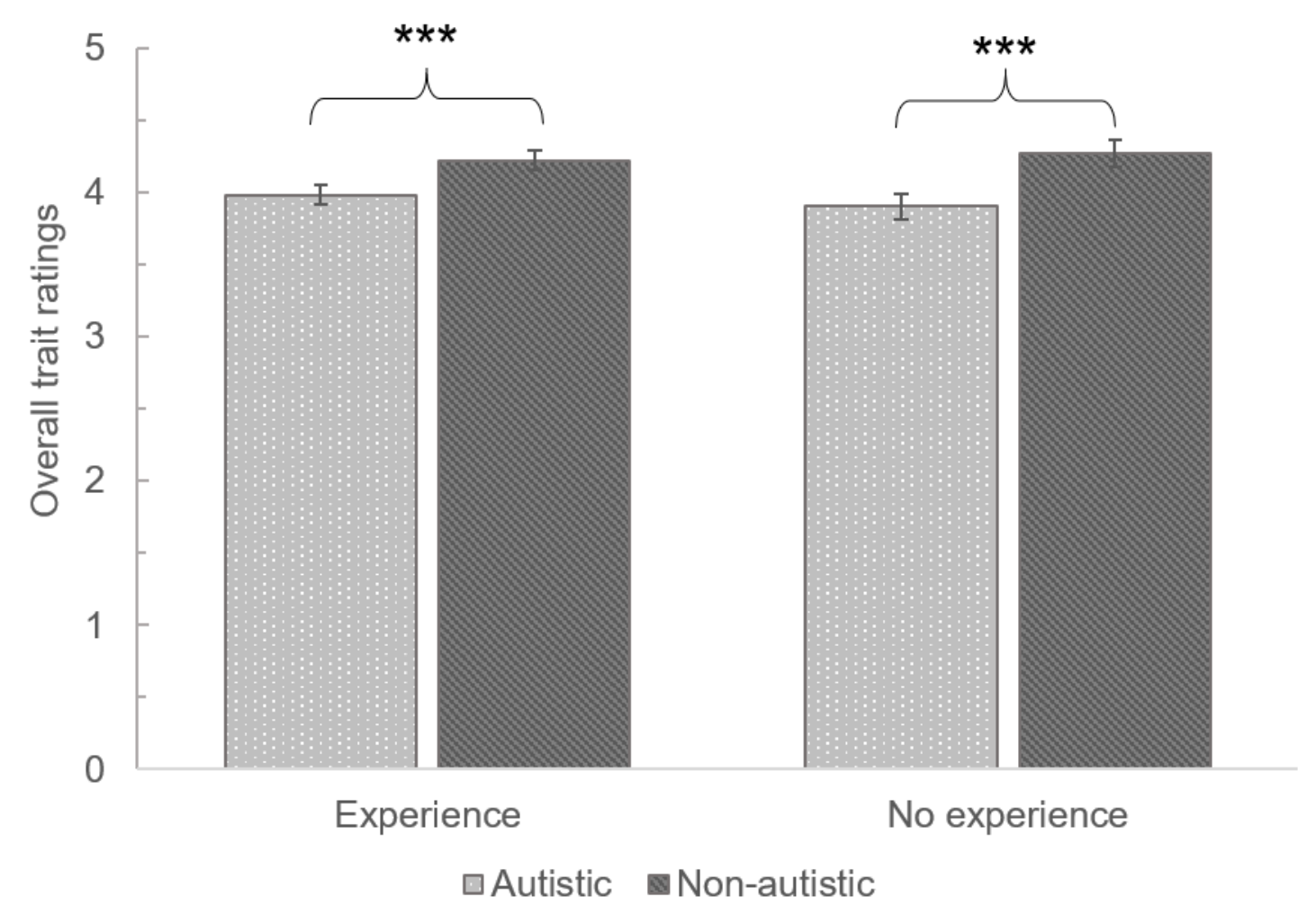

Figure 2. Mean overall trait ratings of autistic and non-autistic people for those with and without experience. Note $* * * \mathrm{p}<.001$. Error bars indicate $+/-2 \mathrm{SE}$ 


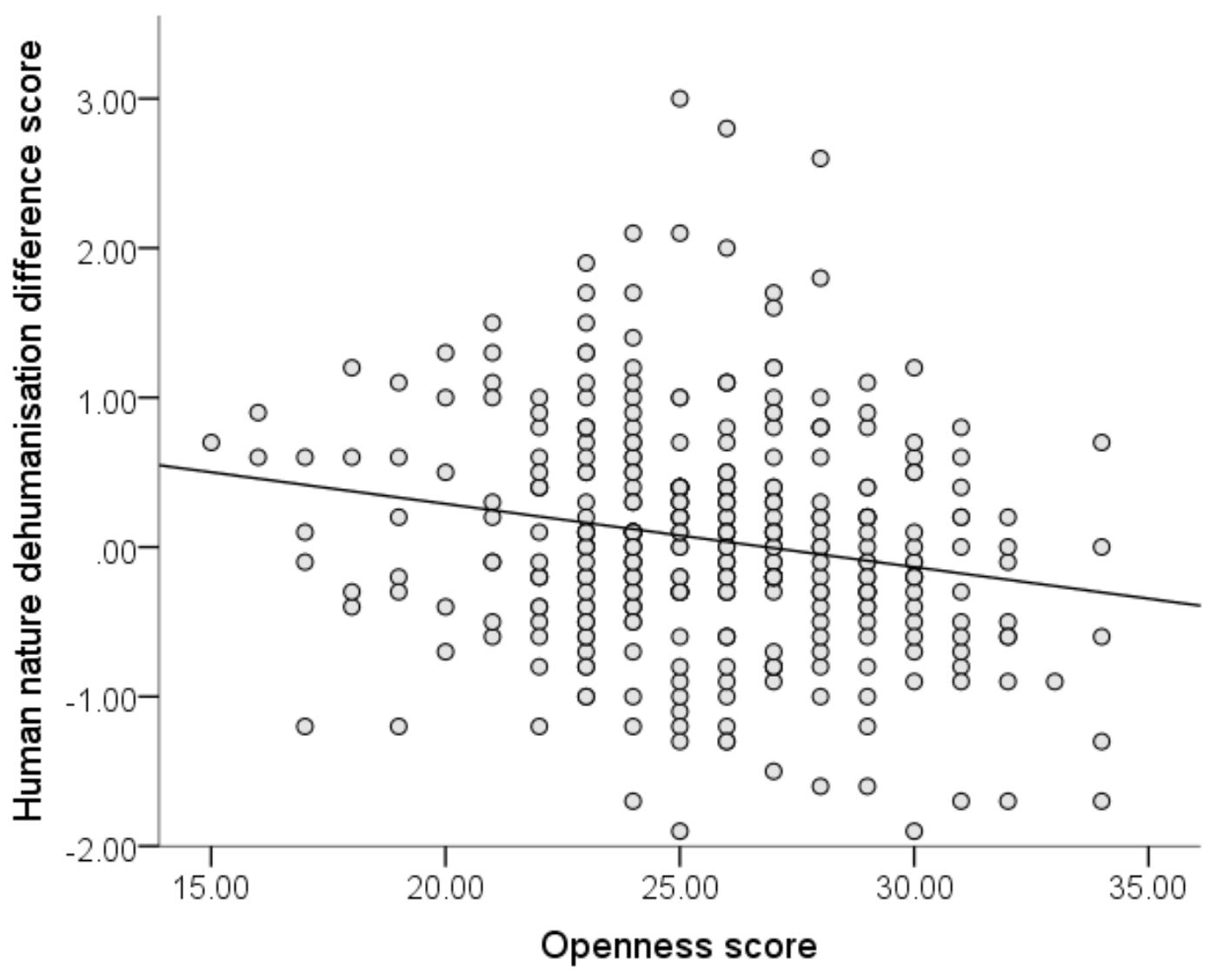

Figure 3. Relationship between openness to autism and human nature traits dehumanisation difference score. 